\title{
Traduzir não o que as palavras dizem, mas o que elas fazem
}

\section{Traduire ce que les mots ne disent pas, mais ce qu'ils font ${ }^{*}$}

Henri Meschonnic

\author{
Tradução de \\ Clarissa Prado Marini** \\ Alice Maria de Araújo Ferreira ${ }^{* *}$
}

Resumo: Continuando sua reflexão e trabalho sobre ritmo, o autor mostra como a poética da tradução pode ultrapassar os limites de uma teoria do signo baseada na dicotomia sentido/forma. Como uma alternativa para essa abordagem, que situa o poema e a tradução numa lógica da descontinuidade, o autor propõe que língua(gem) e tradução possam ser reconsideradas do ponto de vista da continuidade do discurso e da unidade do ritmo. Consequentemente, tradução consiste na tradução não do

\footnotetext{
" N. das T.: Artigo primeiramente publicado em 1995, na revista canadense Meta : journal des traducteurs. Num segundo momento, um trecho deste texto foi transformado num capítulo do livro Poétique du traduire (1999). A presente tradução foi autorizada pelo editor-chefe da Revista Meta : journal des traducteurs / Meta: Translators' Journal, Prof. Dr. Georges L. Bastin, por e-mail, em 29 de agosto de 2016. Pela autorização em traduzir e publicar a tradução, agradecemos muitíssimo. Referência bibliográfica completa do artigo original:

MESCHONNIC, Henri. "Traduire ce que les mots ne disent pas, mais ce qu'ils font". In : Meta : journal des traducteurs / Meta: Translators' Journal. Montréal. vol. 40, $\mathrm{n}^{\circ}$ 3, 1995. p. 514517. Disponible sur : < http://id.erudit.org/iderudit/003640ar >. Acesso em: 01 fev. 2017.

** Doutoranda pela Universidade Federal de Santa Catarina.

**** Docente da UnB.
} 
que as palavras dizem, mas do que elas fazem. Como exemplo, o autor aplica essa abordagem na tradução dos famosos dois primeiros versículos do Salmo 22.

Palavras-chave: Henri Meschonnic, tradução, Salmo 22.

Abstract: Continuing his reflection and work on rhythm, the author shows how a poetics of translation can overcome the limits of a theory of sign based on the meaning/form dichotomy. As an alternative to this approach, which situates the poem and the translation in a logic of discontinuity, the author proposes that language and translation be reconsidered from the viewpoint of the continuity of discourse and the unity of rhythm. Consequently, translation consists in translating not what words say, but what they do. As an example, the author applies this approach to the translation of the famous first two verses of Psalm 22.

Keywords: Henri Meschonnic, Translation, Psalm 22. 
MESCHONNIC, H.; tradução de C. P. Marini e A. M. de A. Ferreira - Traduzir não o que as palavras dizem, mas o que elas fazem

O problema teórico de uma poética da tradução, isto é, da tradução dos textos que são ditos literários, porque eles são uma poética em ato hoje, é antes por fim ao torniquete no qual o pseudo-bom senso geralmente limitou a tradução dos textos literários até aqui.

Esse torniquete é a oposição dos constituintes do signo ${ }^{2}$. Nos limites do signo, onde o significado vale pela totalidade do signo, e o significante é uma forma escamoteável-escamoteada, mantida como um resíduo, a tradução apenas tem a escolha entre traduzir o sentido, é o que Eugene Nida chamou de equivalência dinâmica, ou traduzir, querer traduzir, a forma, em busca da equivalência formal. E nos limites do signo, o próprio bom senso quer que privilegiemos o sentido, pois é bem verdade que toda a linguagem é a favor do sentido, a favor da passagem do sentido, em todos os sentidos.

E a coisa literária, tolamente, se deixou enganar, ao ponto de acreditarmos honestamente que quanto mais essa coisa é literária, mais ela é consubstancial à forma na linguagem (como se o sentido fosse uma substância - o que é estranho se, como podemos pensar desde de Saussure, a linguagem inteira é forma e não substância). Assim a poesia, normalmente percebida como um extremo da coisa literária, era naturalmente consagrada a estar situada no cúmulo da forma. A que se prestavam as formas literárias. Fixas ou não.

Mas se o pensamento dessas coisas leva a pensar o que não é pensado nos limites do signo, podemos conceber, somos até obrigados a conceber 0 que os conceitos costumeiros impedem de pensar. Por isso a poética se torna um olhar sobre a teoria geral da linguagem. 0 olhar do esquecido do signo.

Daí o signo aparece com seus limites. Enquanto que se olharmos a linguagem a partir do signo, não há limites, ele é toda a linguagem, sua própria natureza. Mas, visto do poema, o signo é o descontínuo. Tudo nele e

\footnotetext{
${ }^{2}$ N. do A.: Desenvolvo o que aqui está implícito em Politique du rythme, politique du sujet, Verdier, 1995, que por sua vez vem na sequência de Critique du rythme. Anthropologie historique du langage, Verdier, 1982.
} 
MESCHONNIC, H.; tradução de C. P. Marini e A. M. de A. Ferreira - Traduzir não o que as palavras dizem, mas o que elas fazem

por ele é do descontínuo - o descontínuo entre língua e literatura, língua e cultura; entre a linguagem e o corpo, entre a voz e o escrito, entre a palavra e a coisa, entre o som e o sentido. De uma palavra a outra como de uma língua a outra. E nem lembro de todos. A partir daí a gente tenta o que pode, e há muito tempo, para conseguir juntar as pontas. Ensaiamos isso pela expressividade, corremos atrás da natureza no abandono do convencionalismo, o poema é essa famosa "hesitação prolongada entre o som e o sentido".

Traduzir se instalou nessa situação babélica. Traduzimos sentido, palavras, frases, línguas. Como fazer diferente, como conceber que seja diferente? Como conceber outra coisa senão a anterioridade do compreender e do interpretar, em relação ao traduzir? Situação conhecida. Fim da história, tudo está entendido.

Mas se o interesse de pensar a linguagem continua, é por que existe o desconhecido na linguagem. E talvez tampouco haja progresso no pensamento da linguagem como na arte. Em que a coisa literária e seu impulso de traduzir, mostrariam talvez que na medida em que há ciências da linguagem (variando conforme a época, aliás), haveria uma arte de pensar a linguagem, que pensar a linguagem, e pensar o traduzir, participariam também de uma arte, distinta da arte da linguagem e da arte do traduzir.

Pois o que deve ser pensado é o contínuo na linguagem, e esse contínuo precisa que sejam inventados conceitos para pensá-lo. Para compreender, fazer e analisar o contínuo entre o corpo e a linguagem, entre uma língua e uma literatura, entre uma língua e uma cultura. De fato, trata-se de conseguir pensar o discurso com conceitos do discurso, não os conceitos da língua.

É aqui que o ritmo, não mais na sua acepção platônica, mas como uma organização do movimento da palavra na escrita, como sistema de uma subjetivação generalizada, abre uma conceptualidade que não é mais a do signo. E que pode permitir reconhecer o que sempre existiu, mesmo que o 
MESCHONNIC, H.; tradução de C. P. Marini e A. M. de A. Ferreira - Traduzir não o que as palavras dizem, mas o que elas fazem

signo não permitisse que soubéssemos. Nessa escuta, não há mais uma dupla articulação da linguagem - dos fenômenos, das palavras. Mas uma semântica serial, e o que depois de Apollinaire, mesmo que em um outro sentido que ele, eu chamo de prosódias pessoais.

Já se confundiu demais a literatura com a narrativa. Trata-se aqui de reconhecer que o que cada vez define especificamente a coisa literária, é o recitativo.

Essa nova situação teórica modifica o estatuto do traduzir. Não se trata mais de se precipitar em direção à equivalência formal. Pois a equivalência formal é apenas um efeito da teoria do signo, e ligada também ao seu oposto aparente, a equivalência dinâmica, que o som e o sentido estão ligados no signo.

É o sistema do discurso que é a unidade, para a poética. Todas as outras unidades são de outra ordem, retóricas ou culturais. A equivalência e a concordância não são mais lexicais, mas da ordem dos paradigmas e dos sintagmas de uma semântica serial. Assim a poética da tradução não deve mais ser situada num literalismo, como os guardiões do signo amam tanto fazer $^{3}$. No papel da vilã. Com uma ideia bem mesquinha da poesia, também. Confundindo essa com o verso.

Como uma felicidade nunca vem só, tanto o traduzir sai da oposição entre literalismo e pragmatismo, se situando no contínuo, quanto ele pode pensar em inverter esse truísmo inabalável na aparência, segundo o qual interpretar deve preceder traduzir.

\footnotetext{
${ }^{3} \mathrm{~N}$. do A.: 0 que estava justificado, quando a unidade era a palavra (como ela era no calco, de Chouraqui), não o ritmo e a prosódia. É por um tal mal entendido que Michel Ballard continua vendo naquilo que entendo por poética da tradução uma defesa do "literalismo como absoluto", em De Cicéron à Benjamin (Presses Universitaires de Lille, 1992: 185), ao ponto de tomar minha tradução (ibid. p. 51) como um palavra por palavra puramente explicativo que eu acompanho uma transcrição fonética dos cinco primeiros versos da Gênese, em Pour la poétique II (Gallimard, 1973: 429), enquanto proponho mais a frente (1973: 450) uma tradução, que não tem nada de palavra por palavra, depois do estudo do texto hebreu e de um certo número de traduções. Nessa leitura precipitada, Michel Ballard concluiu uma apologia do literalismo.
} 
Meschonnic, H.; tradução de C. P. Marini e A. M. de A. Ferreira - Traduzir não o que as palavras dizem, mas o que elas fazem

Pois, se olharmos a partir do contínuo, podemos ver através do paralogismo que ele dava como evidente, e que pelo contrário, aparece agora como uma das condições que fazem as traduções ruins.

Pois não se trata, evidentemente, de deixar entender esse absurdo que poderíamos traduzir antes de compreender. Mas de revelar que se colocarmos a tradução como termo de uma cadeia interpretativa, realizaremos necessariamente uma tradução que não fará mais o que faz o texto que se traduz. Pois o texto é portador da cadeia e a tradução é somente portada.

O problema poético é então de fazer com que, estando no momento presente de um saber filológico e hermenêutico, a poética constitui a tradução mais do que a filologia e a hermenêutica, para que, poética por poética, a tradução, simplesmente, texto por texto, coerência por coerência, sistematicidade por sistematicidade, oralidade por oralidade, seja por sua vez não somente portada, mas portadora.

É o que, empiricamente, sempre fizeram as grandes traduções, aquelas que duram. Elas sempre fizeram o contrário do que ensinam hoje aqueles que ensinam que se deve apagar a distância linguística, cultural, histórica; dar a impressão que o texto foi escrito na língua de chegada para o aqui-agora do leitor; apagar o tradutor que deveria ser transparente (e modesto). Sem ver que o acúmulo de tantas transparências tem como resultado exatamente essa sorte particular de opacidade que faz com que, ao ter uma dessas traduções nas mãos, não se veja nada além dos apagamentos: uma retórica no lugar de uma poética, o obsceno de tudo o que estava escondido que se mostra e que recobre o texto no lugar do que acreditávamos ser o traduzir. Traduziu-se sobretudo a época, seus clichês e seus gostos.

É então somente quando a poética é uma crítica da teoria geral da linguagem que podemos ver melhor que a tradução não está sozinha. Acreditar que ela seja autônoma é imediatamente cortá-la da poética restrita das obras assim como da poética geral da linguagem. 
MESCHONNIC, H.; tradução de C. P. Marini e A. M. de A. Ferreira - Traduzir não o que as palavras dizem, mas o que elas fazem

Imediatamente ela se junta ao que ela nunca deixou realmente, o signo e suas estratégias, particularmente aquelas de certas filosofias que nunca souberam o que fazer com um poema, a não ser anexá-lo, e afundar o traduzir numa generalização do compreender. A essencialização é então um diferimento indefinido do empírico. Ou seja, do contínuo.

Usarei aqui apenas um exemplo concreto do contínuo no discurso. A partir do qual a tradução bifurca, longe do que dizem as palavras, segundo seus sentidos, o sentido do dicionário, em direção ao que elas mostram, mas não dizem, em direção ao que elas fazem, que é mais sutil do que o que a pragmática contemporânea acreditou ter revelado.

Trata-se dos dois primeiros versículos do Salmo 22. Já ouve bastantes traduções, quase todas parecidas, que vale a pena uma experiência que nos dê a entender o que ressoa silenciosamente nesse texto. 0 segundo versículo, famoso por ter sido citado por Jesus na cruz em Mateus (XXVII: 46): "Eli, Eli, lama sabakhthani? C'est-à-dire Mon Dieu, mon Dieu, pourquoi m'as-tu abandonné ?” [“Eli, Eli, lama sabakhthani? Isto é Meu Deus, meu Deus, por que me abandonaste? "].

O primeiro versículo tratado como uma didascalia e uma fantasiosa alusão a algo conhecido:

“Pour le coryphée. Sur 'Biche de l'aurore' Psaume de David” (Dhorme);

[“Para o corifeu. Sobre ‘Corça da aurora’ Salmo de Davi”]

A Bible de Jérusalem:

"Du maître de chant. Sur 'La Biche de l'aurore'. Psaume. De David”;

["Do mestre do canto. Sobre 'A corça da aurora'. Salmo. De Davi”] 
MESCHONNIC, H.; tradução de C. P. Marini e A. M. de A. Ferreira - Traduzir não o que as palavras dizem, mas o que elas fazem

$$
\text { A T.O.B. }{ }^{4} \text { : }
$$

"Du chef de chœur, sur 'Biche de l'aurore'. Psaume de David";

[“Do chefe de coro, sobre 'Corça da aurora'. Salmo de Davi”]

O Rabbinat de 1899:

"Au chef des chantres. D'après l'Ayyelet Hachahar5. Psaume de David";

[“Ao chefe dos chantres. Segundo Ayyelet Hachahar. Salmo de Davi”]

\section{Chouraqui:}

"Au chorège. Sur : 'Biche de l'aube'. Chant. De David”.

[“Ao corego. Sobre: 'Corça da aurora'. Canto. De Davi”]

Vemos que as variantes não mudam nada.

Quanto ao $2^{\circ}$ versículo, da Septuaginta a Jerônimo (Deus Deus meus quare dereliquisti me), a King James version (why hast thou forsaken me), a Lutero (warumb hastu mich verlassen) em 1545, e a Buber e Rosenzweig, a Lemaistre de Sacy, ao Rabbinat, a Segond, à Bible de Jérusalem, à T.O.B., a Chouraqui e nas outras línguas europeias nas quais verifiquei, todas incluíram e traduziram pourquoi m'as-tu abandonné [por que me abandonaste].

Ora, a palavra que todos traduzem, no primeiro versículo, para designar o chefe do coro, lamenatséah, contém uma alusão, entendida em hebraico, a netsah, a vitória, e uma antiga tradição de comentário interpretava uma alusão a Deus; a palavra que signa la biche [a corça], ayyélet (mas a "biche de l'aurore" [corça da aurora] é a étoile du berger

\footnotetext{
${ }^{4}$ N. das T.: Traduction oecuménique de la Bible [Tradução ecumênica da Bíblia]

${ }^{5}$ N. do A.: Palavra por palavra: Biche de l'Aurore [Corça da Aurora].
} 
MESCHONNIC, H.; tradução de C. P. Marini e A. M. de A. Ferreira - Traduzir não o que as palavras dizem, mas o que elas fazem

[estrela do pastor]), tem um eco no versículo 20 do mesmo salmo, eyalouti, "ma force" [minha força] (poder, vigor).

Então eu traduzi ${ }^{6}$, mas São Jerônimo já traduzia Victori (pro cervo matutino canticum):

De qui la victoire

[De quem a vitória sur la force de l'aube

sobre a força da aurora un chant de David

um canto de Davi]

Quanto ao $2^{\circ}$ versículo, Samson Raphael Hirsch ${ }^{7}$, de meu conhecimento, foi o único a notar que a palavra traduzida por pourquoi [por que], lama, tem esse sentido se for acentuada na primeira sílaba, mas aqui é acentuada na segunda e não tem esse sentido (ele traduz "for what purpose") e eu traduzo:
Mon Dieu mon Dieu
à quoi m'as-tu abandonné
[Meu Deus meu Deus
a que me abandonaste]

que muda o sentido, antropologicamente e teologicamente. Acessoriamente, os dois Mon Dieu mon Dieu fazem um só grupo, de um só fôlego, sem pontuação entre eles, como fazem os outros, e o impalpável do modo de significar, afetivamente, modifica não apenas o sentido, mas o valor.

E é por que traduzir faz uma poética experimental - por que existe o retraduzir - que a poética da tradução é necessária à poética das obras tanto quanto esta lhe é necessária. 0 signo é velho e surdo.

E o essencial, com a linguagem, é ouvir, incluso aí tudo o que o sentido, o reino do sentido, nos impede de ouvir.

\footnotetext{
${ }^{6} \mathrm{~N}$. do A.: Sobre a montagem de Claude Régy, no programa da Opéra de Paris-Bastille, para Jeanne d'Arc au bûcher, oratório de Claudel e Honegger, novembro 1992. Os espaços em branco são os mesmos empregados nas minhas traduções de Cinq Rouleaux (Gallimard, 3e éd., 1995) e de Jona et le signifiant errant (Gallimard, 1981).

7 N. do A.: The Psalms, Translation and Commentary by Rabbi Samson Raphael Hirsch, Feldheim Publishers, Jerusalem/New York, 1978 [1880].
} 
MESCHONNIC, H.; tradução de C. P. Marini e A. M. de A. Ferreira - Traduzir não o que as palavras dizem, mas o que elas fazem

Data de submissão: 21/02/2017

Data de aprovação: 27/06/2017

TradTerm, São Paulo, v. 29, Julho/2017, p. 206-215 -

www.usp.br/tradterm 